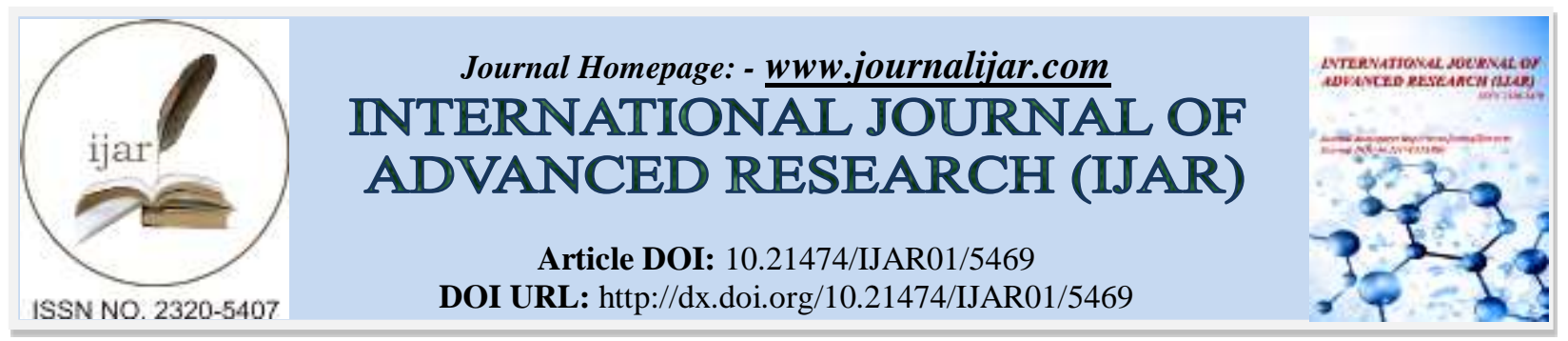

RESEARCH ARTICLE

\title{
MAIN CONSIDERATIONS ABOUT FRACTION GENERATED BETWEEN BRACKETS AND LIGATURES: BRIEF COMMENTS.
}

\author{
Francielle de Almeida Souza ${ }^{1}$, Idiberto José Zotarelli Filho ${ }^{2}$, Leandro Moreira Tempest ${ }^{1,2}$ and Carlos Alberto \\ Costa Neves Buchala ${ }^{1,2}$. \\ 1. University Center North Paulista (Unorp) - São José do Rio Preto - SP, Brazil. \\ 2. Post graduate and continuing education (Unipos), Street Ipiranga, 3460, São José do Rio Preto SP, Brazil \\ 15020-040.
}

\section{Manuscript Info}

\section{Manuscript History}

Received: 19 July 2017

Final Accepted: 21 August 2017

Published: September 2017

Key words:-

Self-ligating bracket, Friction, tooth movement, Orthodontic, brackets.

\section{Abstract}

The demand for orthodontic treatment has grown exponentially. In large part, the demand has been for devices self-ligating, because some articles have reported a shorter time of treatment in relation to the conventional apparatus. By means of literature review, this work had the objective of studying and comparing the frictional forces that occur during the treatment, between conventional / Self-ligating brackets in contact with orthodontic wires. And forces generated when using conventional and unconventional bandages in conventional brackets.

Copy Right, IJAR, 2017,. All rights reserved.

\section{Introduction:-}

The search for orthodontic procedures has grown exponentially. Dental procedures, in addition to seeking the principle of health promotion, seek the aesthetics of the smile, being a form of communication and socialization that expresses various feelings [1,2].

It is known that the friction force decreases the effectiveness of the dental movements of the bracket along the orthodontic wire, where studies have been carried out to reduce it in Orthodontics. This study has been of great importance over time, since there was an increase in the use of slide mechanics [3,4]. Clinically, a tooth that is subjected to the sliding movement along the arch undergoes alternating tilting and verticalization movements, where it moves in small increments. However, the closure of spaces depends more on static than on kinetic friction [4,5].

Self-ligating brackets are non-banded brackets that feature a mechanical device designed in the bracket to close the Edgewise bracket [6]. There are three types of self-ligating brackets according to the degree of system pressure applied to the wire: Active when the system presses the wire into the gutter, Passive when the system allows freedom of wire in the gutter, Interactive when self-ligating brackets exert pressure In thicker yarns, but allow for freedom from less-gauge yarns. Whether they are active or passive self-ligating brackets, the fourth movable wall of this bracket converts the slot into a tube [7]. When the active bracket system is used, the friction is much greater than when using the passive bracket system [8].

The conventional brackets, unlike the self-ligating ones, require ligatures, whether elastic or metallic, to perform the closure, to house the orthodontic wire $[9,10]$.

Corresponding Author:- Idiberto José Zotarelli Filho.

Address:- Post graduate and continuing education (Unipos), Street Ipiranga, 3460, São José do Rio Preto SP, Brazil. 
The objective of this study was to present the main considerations about the frictional forces that occur during orthodontic treatment between conventional and self - ligating brackets in contact with several orthodontic wires. And the forces generated when conventional and unconventional bandages are placed in conventional brackets.

\section{Methodology:-}

Experimental and clinical studies were included (case reports, retrospective, prospective and randomized trials) with qualitative and / or quantitative analysis. Initially, the key words were determined by searching the DeCS tool (Descriptors in Pubmed, Health Sciences, BIREME base) and later verified and validated by MeSh system (Medical Subject Headings, the US National Library of Medicine) in order to achieve consistent search.

\section{Mesh Terms:-}

The words were included Self-ligating bracket, Friction, tooth movement, Orthodontic, brackets. The literature search was conducted through online databases: Pubmed, Periodicos.com and Google Scholar. It was stipulated deadline, and the related search covering all available literature on virtual libraries.

\section{Series of Articles And Eligibility:-}

A total of 30 articles were found involving Self-ligating bracket, Friction, tooth movement, Orthodontic, brackets. Initially, it was held the exclusion existing title and duplications in accordance with the interest described this work. After this process, the summaries were evaluated and a new exclusion was held. A total of 22 articles were evaluated in full, and 12 were included and discussed in this study.

\section{Brief Comments:-}

The friction is a force that resists the movement of two bodies with tangential direction to the plane of contact. There are two types of friction, static and kinetic [1-3]. Static friction is the smallest force required to initiate a movement between a solid object that is at rest [3,4]. On the other hand, the force of kinetic friction is that which resists the movement of sliding from one solid object to another, at a constant velocity [5]. The kinetic friction is always smaller than the static one, because it is more difficult to take a body out of the rest situation than to perpetuate the movement [6].

Several studies have demonstrated a significant decrease in friction for self-attached brackets, compared to conventional bracket models [7]. This reduction may help reduce treatment time, especially in patients with extraction in which tooth translation is achieved by means of sliding mechanics [8].

Among the studies carried out, Voudouris measured the friction produced by three types of conventional brackets and compared them to three types of self-ligating brackets: one active and two passive [9]. When 0.019 "x 0.025" steel arches were engaged, a conventional "O" banded bracket produced friction between 371 times and 667.8 times greater than passive self-ligating brackets [10]. Conventional brackets with metallic ligatures presented friction values up to 532.8 times higher than passive self-ligating brackets $[11,12]$. The self-sufficient assets produced up to 310 times greater than the self-liable liabilities [12].

\section{Conclusion:-}

Conventional ligatures with conventional ligatures showed higher frictional force, when unconventional ligatures "8" and "88" were applied, they showed results that were similar between them, with lower friction values. The selfligating brackets have confirmed a higher friction control, generating static and kinetic friction forces considerably lower than conventional brackets. If the wire size was enlarged, all brackets had higher static and kinetic friction forces.

\section{Competing Interests:-}

The authors none declare. 


\section{References:-}

1. Baccetti T, Franchi L. Friction produced by types of elastomeric ligatures in treatment mechanics with the preadjusted appliance. Angle Orthod. 2006 Mar;76(2):211-6.

2. Baker KL, Nieberg LG, Weimer AD, Hanna M. A comparative study of frictional resistances between orthodontic bracket and archwire. Am J Orthod Dentofac Orthop. 1987;91(4):316-20.

3. Baty DL, Volz JE, Von Fraunhofer JA. Force properties of colored elastomeric modules. Am J of Orthod Dentofacial Orthop. 1994 Jul;106(1):40-6.

4. Boester $\mathrm{CH}$, Johnston LE. A clinical investigation of the concepts of differential and optimal force in canine retraction. Angle Orthod. 1974 Apr;44(2):113-9.

5. Brauchli LM, Senn C, Wichelhaus A. Active and passive self- -ligation - a myth? Angle Orthod. 2011 Mar;81(2):312-8.

6. Burrow SJ. Friction and resistance to sliding in orthodontics: a critical review. Am J of Orthod and Dentofac Orthop. 2009 Apr;135(4):442-7.

7. Cacciafesta V, Sfondrini MF, Ricciardi A, Scribante A, Klersy C, Auricchio F. Evaluation of friction of stainless steel and esthetic self-ligating brackets in various bracket-archwire combinations. Am J Orthod Dentofac Orthop. 2003 Oct;124(4):395-402.

8. Chen SS, Greenlee GM, Kim JE, Smith CL, Huang GJ. Systematic review of self-ligating brackets. Am J Orthod Dentofacial Orthop. 2010 June;137(6):726.e1-726.e18; discussion 726-7.

9. Dholakia KK, Bhat SR. Clinical efficiency of nonconventional elastomeric ligatures in the canine retraction phase of preadjusted edgewise appliance therapy: an in-vivo study. Am J Orthod Dentofacial Orthop. 2012 June;141(6):715-22.

10. Huang TH, Luk HS, Hsu YC, Kao CT. An in vitro comparison of the frictional forces between archwires and self-ligating brackets of passive and active types. Eur J Orthod. 2011 Jul 16. [Epub ahead of print].

11. Jean Rafael Geremia, Pablo Santos de Oliveira, Rogério Heládio Lopes Motta. Comparison of friction among self-ligating brackets and conventional brackets with different ligadures. Orthod. Sci. Pract. 2015; 8(29):30-37.

12. Tecco S, Di Loiro D, Nucera R, Di Bisceglie, Cordasco G, Festa F. Evaluation of the friction of self-ligating and conventional bracket sistems. Eur J Dent. 2011 July;5(3):310-7. 